\title{
Suicidality in primary care patients who present with sadness and anhedonia: a prospective European study
}

\author{
Berta Moreno-Küstner ${ }^{1}$, Rebeca Jones ${ }^{2}$, Igor Švab ${ }^{3}$, Heidi Maaroos ${ }^{4}$, Miguel Xavier $^{5}$, Mirjam Geerlings ${ }^{6}$, \\ Francisco Torres-González ${ }^{7}$, Irwin Nazareth ${ }^{8}$, Emma Motrico-Martínez ${ }^{9}$, Carmen Montón-Franco ${ }^{10}$, \\ María José Gil-de-Gómez ${ }^{11}$, Marta Sánchez-Celaya ${ }^{12}$, Miguel Ángel Díaz-Barreiros ${ }^{13}$, Catalina Vicens-Caldentey ${ }^{14}$ \\ and Michael King ${ }^{2 *}$
}

\begin{abstract}
Background: Sadness and anhedonia (loss of interest in activities) are central symptoms of major depression. However, not all people with these symptoms meet diagnostic criteria for major depression. We aimed to assess the importance of suicidality in the outcomes for primary care patients who present with sadness and anhedonia.

Method: Cohort study of 2,599 unselected primary care attenders in six European countries followed up at 6 and 12 months.

Results: 1) In patients with sadness and/or anhedonia who were not depressed at entry to the study, suicide plans $(\mathrm{OR}=3.05 ; 95 \% \mathrm{Cl}=1.50-6.24 ; p=0.0022)$ and suicide attempts ( $\mathrm{OR}=9.08 ; 95 \% \mathrm{Cl}=2.57-32.03 ; p=0.0006)$ were significant predictors of developing new onset depression at 6 or 12 months. 2) In patients with sadness and/or anhedonia who met $\mathrm{CIDI}$ criteria for major depression at entry, suicidal ideation $(\mathrm{OR}=2.93 ; 95 \% \mathrm{Cl}=1.70-5.07$; $p=0.0001)$, suicide plans $(\mathrm{OR}=3.70 ; 95 \% \mathrm{Cl}=2.08-6.57 ; p<0.0001)$, and suicide attempts $(\mathrm{OR}=3.33 ; 95 \%$ $\mathrm{Cl}=1.47-7.54 ; p=0.0040$ ) were significant predictors of persistent depression at 6 or 12 months.
\end{abstract}

Conclusions: Three questions on suicidality could help primary care professionals to assess such patients more closely without necessarily establishing whether they meet criteria for major depression.

Keywords: Anhedonia, Depression, Primary care, Suicidality, Cohort, Risk

\section{Background}

Major depression is a relatively common disorder in primary care and is characterised by relapse and remission [1]. It can have serious consequences in terms of total burden of disease [2] and costs to society [3]. Premature deaths may be due to associated physical morbidity as well as death from unnatural causes such as suicide [4]. Suicidal ideation is a core symptom of major depression [5-7]. Sadness and loss of interest in activities (anhedonia) are central symptoms of major depression and thus questions about them are useful in screening people for the

\footnotetext{
* Correspondence: michael.king@ucl.ac.uk

²Division of Psychiatry, UCL, London, UK

Full list of author information is available at the end of the article
}

disorder. However, not all people with these symptoms meet diagnostic criteria for major depression. The depression section of the Composite International Diagnostic Interview (CIDI) begins with these two key questions and people who answer affirmatively to one or both continue with the interview to establish whether or not they meet criteria for the disorder [8]. Suicidal ideation is also a symptom of major depression ${ }^{1}$ but, like sadness and anhedonia, it may occur in the absence of a diagnosis of major depression. There is a lack of knowledge about depression outcomes in patients who screen positive for anhedonia and sadness, irrespective of whether or not they have a diagnosis of major depression. We aimed to study the outcomes of patients who are found to have sadness and anhedonia when they attend their family doctors. In particular, we examined whether the presence of suicidal 
ideation, plans and attempts had any predictive role in the onset or persistence of depressive disorder over 6 or 12 months follow-up.

\section{Method}

\section{Study design}

We analysed data from the Predict Europe (PE) and Predict Spain (PS) prospective cohorts, which were recruited to develop and validate a risk prediction algorithm for the onset of major depression in primary care attendees over 12 months. The PE and PS studies, which were conducted in six European countries, have been described in detail elsewhere [9-13]. They were approved by relevant ethical committees (The South East Multi-centre Research Ethics Committee) in each country.

\section{Setting}

In the PE study, six European centres participated: 1) 25 general practices in the Medical Research Council's General Practice Research Framework, distributed across the United Kingdom; 2) nine large primary care centres in Andalucía, Southern Spain; 3) 74 general practices distributed nationwide in Slovenia; 4) 23 general practices distributed nationwide in Estonia; 5) seven large general practice centres near Utrecht, The Netherlands; and 6) two large primary care centres in urban and rural areas of Portugal that include 25 general practitioners. In the PS study, seven provinces participated with 41 health centres and 231 physicians distributed throughout Spain: Malaga and Granada in southern Spain; Saragossa and La Rioja in northern Spain; Madrid, capital of Spain, situated in the centre; Las Palmas in the Canary Islands; and Majorca in the Balearic Islands. Each health centre covered a population of 15,000-30,000 inhabitants from a geographically defined area. The family physicians in each health centre work as a group, with extensive primary care teams.

\section{Participants}

In the PE study, data were collected in consecutive attendees aged 18-75 years between April 2003 and September 2004. In PS, in the six Spanish provinces, the study population was recruited between October 2005 and February 2006. The seventh province, Malaga, recruited between October 2003 and February 2004 as it was already participating in the PE study. Exclusion criteria for all participant countries were an inability to understand the main language of the country, psychosis, dementia, and incapacitating physical illness. In the UK and The Netherlands, patients were recruited in health centre waiting rooms whereas in the other countries recruitment was conducted in discussion with the family physician.

A total of 11,299 people took part in both Predict cohorts $[2,6]$. For this analysis we selected only persons who answered yes to one or both of the two screening questions (on anhedonia and sadness in the preceding six months) of the Depression Section of the Composite International Diagnostic Interview (CIDI) [14, 15]. A total of 7,985 (71 \%) participants answered negatively to both of these CIDI screening questions and were excluded. A total of 3,314 patients answered positively to one or both and were included in this study. We excluded patients with no information about suicidal behavior $(n=27)$, diagnoses $(n=74)$ and those with no follow-up data at 6 and 12 months $(n=614)$.

\section{Measures}

Our outcome variable was a DSM-IV ${ }^{1}$ (Diagnostic and Statistical Manual of Mental Disorders) diagnosis of major depressive disorder as assigned by the Depression Section of CIDI (Version 2.1) [14-16].

Our main exposure of interest was suicidality (comprising ideation, plans and attempts) in the preceding six months, which was also assessed by the CIDI using the following questions:

o Did you feel so low you thought a lot about committing suicide? (ideation)

o Did you make a plan as to how you might do it? (plan)

o Did you attempt suicide? (attempt).

Other explanatory factors

The following baseline variables were considered to be potential confounders of the relationship between suicidal ideas, plans and attempts and major depression at follow up:

- Social and demographic factors: age, sex, civil status, educational level, living alone or with others and debt and financial strain [17].

- Physical and mental well-being, assessed by the 12-item Short Form (SF-12) [18, 19] and a question on the presence of long-standing illness, disability or infirmity.

- Alcohol misuse, assessed by Alcohol Use Disorders Identification Test (AUDIT) [20-22].

- Life-time screen for depression: we used the first two questions of the CIDI $[14,15,21]$ again but this time posed with regard to during their lifetime.

- Anxiety symptoms using the anxiety section of the Primary Care Evaluation of Mental Disorders (PRIME-MD) [23, 24].

- Brief questions on the quality of sexual and emotional relationships with a partner, adapted from a standardized questionnaire [25].

- Childhood experiences of physical, emotional or sexual abuse [26]. 
- Presence of serious physical, psychological or substance misuse problems, or any serious disability, in persons who were close friends or relations of participants.

- Difficulties in getting on with people and maintaining close relationships were assessed using questions from a social functioning scale [27].

- Family history of serious mental disorder and/or suicide in first-degree family members [28].

- Recent life-threatening events, using a brief validated checklist [29].

- Experiences of discrimination on the grounds of sex, age, ethnicity, appearance, disability or sexual orientation using questions from a European study [30].

- Adequacy, availability and sources of social support from family and friends [31].

\section{Statistical methods}

The outcome was major depression at 6 and 12 months follow-up. The main exposure variable was a four category measure of suicidality in the previous 6 months: no suicidal behaviour (reference category); suicidal ideation only; suicide plans; suicide attempts. We performed the statistical analysis separately in non-depressed individuals at baseline - group 1 (for whom a diagnosis of major depression at either 6 or 12 months follow up indicated onset) and in depressed people at baseline-group 2 (for whom a diagnosis of depression at follow up indicated a lack of recovery). We analysed measures of depression from both 6 and 12 months follow-up in a single mixed effects logistic regression model, accounting for correlations between repeated measures over time by specifying a random effect of individual. This method permitted us to include in the analysis individuals with incomplete data at follow-up. In addition, estimating the average odds of depression over the two time points may provide more reliable estimates of depression at follow-up. This was particularly the case among non-depressed people at baseline, where low numbers with a diagnosis of depression at follow-up and low numbers reporting any suicidality at baseline could otherwise result in unreliable and imprecise estimates.

In the first statistical model of the putative relationship between suicidal behaviour and onset or persistence of depression, we adjusted for age, sex, lifetime depression, and country. We then adjusted additionally in turn for each of 20 pre-specified potential confounding variables as detailed above. We accounted for correlations between patients within the same health centre by specifying a random effect of centre in all statistical models.

We performed sensitivity analyses to assess whether our results might be biased by missing follow up data using two different methods: (1) further adjustment for important predictors of missingness, and (2) inverse probability weighting for the probability of outcome data at follow up. Both methods make the assumption that follow up data are missing at random (MAR) conditional on the covariates included in the respective models.

\section{Results}

Our final sample contained 2,599 patients who met CIDI criteria for sadness and/or anhedonia. We divided this sample into two cohorts. The first cohort (group 1) contained participants who were not depressed at baseline $(n=1,412)$. Ninety-four per cent $(n=1,326)$ had followup data at 6 months and $90 \%(n=1,265)$ at 12 months. The second cohort (group 2) consisted of participants who were depressed at baseline $(n=1,187)$, of whom $95 \%(n=1,124)$ had follow-up data at 6 months and $89 \%(n=1,051)$ at 12 months. Frequencies of all the sociodemographic variables assessed in our study are summarized in Table 1. Concerning the distribution of the suicidality, $82.6 \%$ present no suicidal behaviour $(n=2147)$ while, $8.2 \%$ had any suicidal ideation, $6.7 \%$ plans and $2.5 \%$ suicide attempts (Table 2).

\section{Onset of depression in patients who were not depressed at baseline}

Of the 1,412 participants who were not depressed at baseline and attended one or both of the follow up assessments, $13.9 \%(184 / 1,326)$ received a diagnosis of major depression at 6 months, and $13.7 \%(173 / 1,265)$ were depressed at 12 months (Fig. 1). In a model adjusted for age, sex, lifetime depression and country, suicidal ideation in the last 6 months was not a significant predictor of developing new onset depression at 6 or 12 months. However suicide plans in the last 6 months were a significant predictor $(\mathrm{OR}=3.05$; $95 \% \mathrm{CI}=1.50$ to $6.24 ; p=0.0022$ ), as was a history of suicide attempts in the last 6 months $(\mathrm{OR}=9.08$; $95 \% \mathrm{CI}=2.57$ to $32.03 ; p=0.0006$ ) (Table 2). There was no significant interaction between suicidal ideation and sex, or suicidal ideation and a three category measure of age.

\section{Persistent depression in patients who were depressed at baseline}

Of the 1,187individuals, who were depressed at baseline and who attended one or both of the follow up assessments, $34.1 \%(383 / 1,124)$ had persistent depression at 6 months, and $27.1 \%(285 / 1,051)$ at 12 months (Fig. 1$)$. In a similar multivariable model adjusted for age, sex, lifetime depression and country, suicidal ideation in the last 6 months was a significant predictor of persistent depression at 6 or 12 months $(\mathrm{OR}=2.93 ; 95 \% \mathrm{CI}=1.70$ to $5.07 ; p=0.0001$ ), as were suicide plans in the last 6 months $(\mathrm{OR}=3.70 ; 95 \% \mathrm{CI}=2.08$ to $6.57 ; p<0.0001)$, and suicide attempts $(\mathrm{OR}=3.33$; $95 \% \mathrm{CI}=1.47$ to 7.54 ; 
Table 1 Demographic characteristics of the 2,599 participants in Predict Europe and Predict Spain with sadness and anhedonia

\begin{tabular}{|c|c|c|c|c|c|c|}
\hline \multirow[t]{3}{*}{ Demographic characteristics } & \multicolumn{2}{|c|}{ No major depression at baseline } & \multicolumn{2}{|c|}{ Major depression at baseline } & \multicolumn{2}{|l|}{ Total } \\
\hline & \multicolumn{2}{|l|}{$N=1,412$} & \multicolumn{2}{|l|}{$N=1,187$} & \multicolumn{2}{|l|}{$N=2,599$} \\
\hline & $\mathrm{N}$ & $\%$ & $\mathrm{~N}$ & $\%$ & $\mathrm{~N}$ & $\%$ \\
\hline \multicolumn{7}{|l|}{ Country } \\
\hline United Kingdom & 235 & 16.6 & 154 & 13.0 & 389 & 15.0 \\
\hline Spain & 719 & 50.9 & 559 & 47.1 & 1,278 & 49.2 \\
\hline Slovenia & 117 & 8.3 & 68 & 5.7 & 185 & 7.1 \\
\hline Portugal & 110 & 7.8 & 152 & 12.8 & 262 & 10.1 \\
\hline The Netherlands & 113 & 8.0 & 118 & 9.9 & 231 & 8.9 \\
\hline Estonia & 118 & 8.4 & 136 & 11.5 & 254 & 9.8 \\
\hline Age mean (SD) & \multicolumn{2}{|l|}{$49.5(14.9)$} & \multicolumn{2}{|l|}{$45.1(14.0)$} & \multicolumn{2}{|l|}{$47.5(14.7)$} \\
\hline \multicolumn{7}{|l|}{ Sex } \\
\hline Female & 1,080 & 76.5 & 934 & 78.7 & 2,014 & 77.5 \\
\hline Male & 332 & 23.5 & 253 & 21.3 & 585 & 22.5 \\
\hline \multicolumn{7}{|l|}{ Marital status } \\
\hline Married/living with partner & 944 & 66.9 & 738 & 62.2 & 1,682 & 64.7 \\
\hline Separated ordivorced & 119 & 8.4 & 145 & 12.2 & 264 & 10.2 \\
\hline Single & 218 & 15.4 & 234 & 19.7 & 452 & 15.4 \\
\hline Widowed & 131 & 9.3 & 70 & 5.9 & 201 & 7.7 \\
\hline \multicolumn{7}{|l|}{ Level of education } \\
\hline Higher professional, nursing & 287 & 20.3 & 291 & 24.5 & 578 & 22.2 \\
\hline Secondary education and trade & 475 & 33.6 & 406 & 34.2 & 881 & 33.9 \\
\hline Primary or no education & 650 & 46.0 & 490 & 41.3 & 1,140 & 43.9 \\
\hline \multicolumn{7}{|l|}{ Household status } \\
\hline Not living alone & 1,219 & 86.3 & 1,043 & 87.9 & 2,262 & 87.0 \\
\hline Living alone & 193 & 13.7 & 144 & 12.1 & 337 & 13.0 \\
\hline \multicolumn{7}{|l|}{ Financial strain } \\
\hline Comfortable & 1,014 & 71.8 & 746 & 62.8 & 1,760 & 67.7 \\
\hline Difficulties & 398 & 28.2 & 441 & 37.2 & 839 & 32.3 \\
\hline
\end{tabular}

$p=0.0040$ ) (Table 2). Again, we found no significant interaction effects between suicidal ideation and sex, or suicidal ideation and a three category measure of age.

\section{Models with further adjustment}

We found evidence of some degree of confounding in the relationship between suicidality and depression at 6 and 12 months by a number of pre-specified potential confounders, namely financial problems, panic attack, physical or emotional child abuse, sexual abuse, discrimination, social support and mental and physical quality of life (Table 3). Adjustment for a further 12 potential confounders did not materially alter the magnitude of the association, that is they did not affect the odds ratios by more than $5 \%$ (results not shown).

Table 2 Suicidality of the 2,599 participants in Predict Europe and Predict Spain with sadness and anhedonia

\begin{tabular}{|c|c|c|c|c|c|c|}
\hline \multirow[t]{3}{*}{ Suicidality } & \multicolumn{2}{|c|}{ No major depression at baseline } & \multicolumn{2}{|c|}{ Major depression at baseline } & \multicolumn{2}{|l|}{ Total } \\
\hline & \multicolumn{2}{|c|}{$N=1,412$} & \multicolumn{2}{|c|}{$N=1,187$} & \multicolumn{2}{|c|}{$N=2,599$} \\
\hline & $\mathrm{N}$ & $\%$ & $\mathrm{~N}$ & $\%$ & $\mathrm{~N}$ & $\%$ \\
\hline No suicidality & 1230 & 87.1 & 917 & 77.2 & 2147 & 82.6 \\
\hline Suicidal ideation & 93 & 6.6 & 121 & 10.2 & 214 & 8.2 \\
\hline Suicide plan & 70 & 5.0 & 104 & 8.8 & 174 & 6.7 \\
\hline Suicide attemps & 19 & 1.3 & 45 & 3.8 & 64 & 2.5 \\
\hline
\end{tabular}




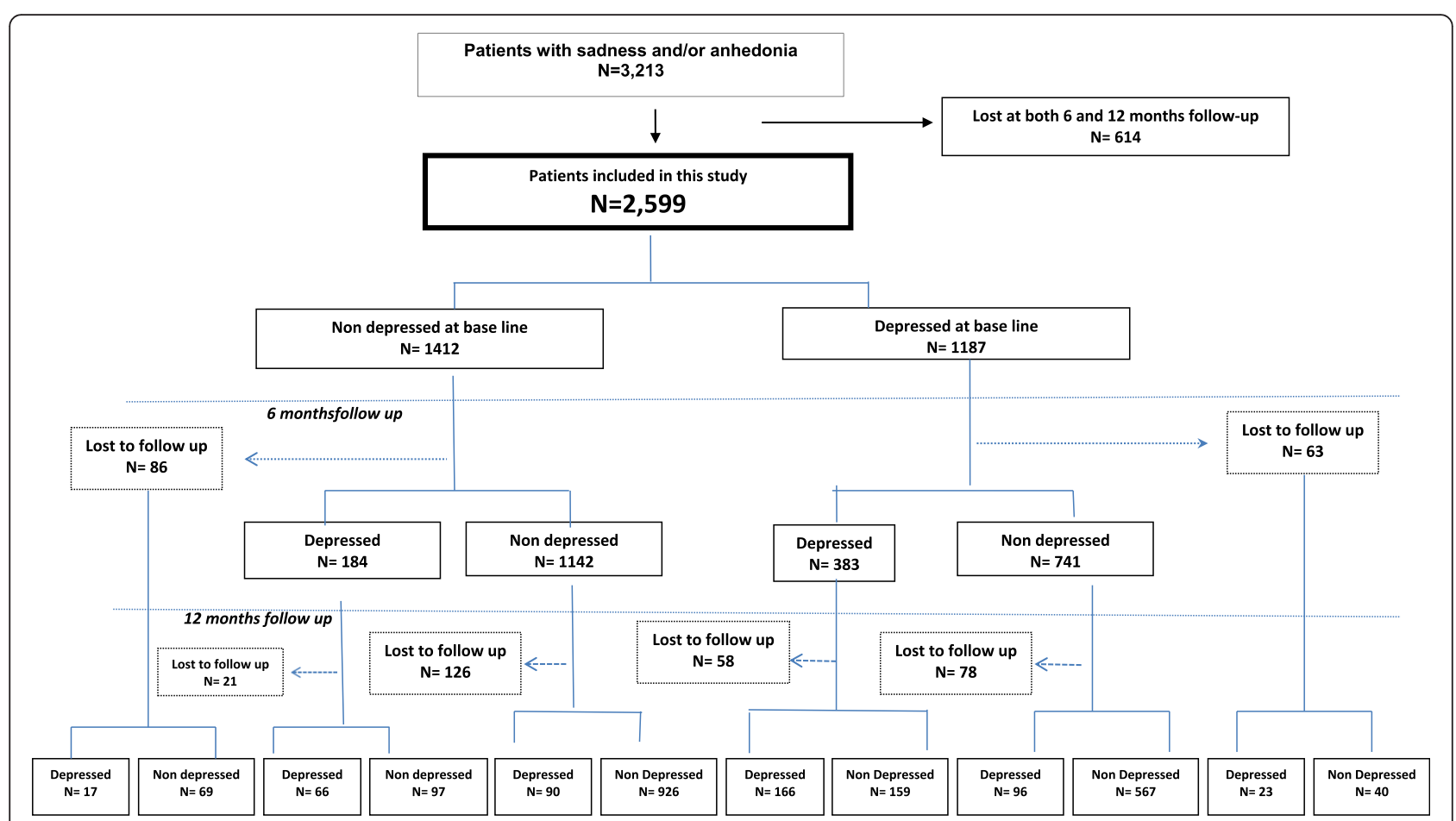

Fig. 1 Flow diagram of recruitment and follow-up

The most important confounder was mental quality of life (SF12 mental health scale), which reduced the magnitude of the ORs for onset of depression in individuals who were not depressed at baseline (by $24 \%$ for patients with suicide plans and $29 \%$ for those with suicide attempts, relative to patients with no suicidality). However, even in this most extreme case, there was still evidence of a strong association between suicidality and the onset of depression, and adjusted ORs remained relatively large in magnitude (OR for onset in individuals with suicide plans: 2.33; $95 \%$ CI: 1.16 to 4.68; OR for onset in individuals with a history of suicide attempts: 6.42 ; $95 \%$ CI: 1.89 to 21.77 ).

In patients who were depressed at baseline, the most important confounder was again mental quality of life (SF12 mental health scale), which reduced the magnitude of the ORs (by $14 \%$ for patients with suicidal ideation, $19 \%$ for those with suicide plans and $21 \%$ for those with suicide attempts, relative to patients with no suicidal behaviour). There was likewise still evidence of a strong association between suicidality and persistent depression, and adjusted ORs again remained relatively large in magnitude (OR for persistent depression in individuals with suicidal ideation: 2.53: $95 \%$ CI: 1.48 to 4.33; OR for persistent depression in individuals with suicide plans: 3.01 ; 95 \% CI: 1.72 to 5.28; OR for persistent depression in individuals with a history of suicide attempts: 2.62; 95 \% CI: 1.18 to 5.79 ).

\section{Sensitivity analysis}

The effect estimates from the further adjusted model (for important predictors of missingness) were very close to the results from the original model, while those from the inverse probability weighting analysis suggested that the original model may have slightly overestimated the association between suicidality and onset of depression and slightly underestimated the association between suicidality and persistent depression (Table 4). However, the results were not substantially different to those from the original analyses in either case, and would not result in any alteration to the conclusions drawn from the initial analysis.

\section{Discussion}

To our knowledge, this is the first study of the natural history of people experiencing sadness and anhedonia who attended primary medical care services and, in particular, of the role of suicidality in the subsequent onset or persistence of major depression. Most information concerning suicidal behaviour and major depression stems from studies of the general population or psychiatric services [32-34]. Considerably less evidence comes from primary care populations [35].

Our basic model (adjusted for age, sex, country and lifetime depression) showed that suicide plans and attempts in the preceding 6 months were significant predictors of both the onset and persistence of major 
Table 3 Association between suicidality (ideation, plans and attempts) and major depression at 6 or 12 months follow up in general practice patients with sadness and/or anhedonia

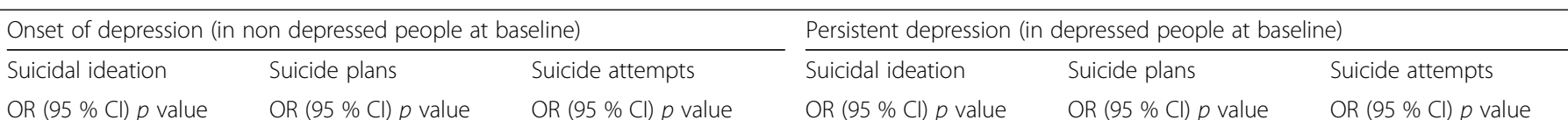

Basic model

Adjusted for age, sex, lifetime depression and country

Further adjusted models

Financial problems

Panic attack

Physical or emotional child abuse

Sexual child abuse

Discrimination

Social support from family and friends

Physical quality of life (SF12)

1.17 (0.58 to 2.37 ) $0.6561 \quad 3.05$ (1.50 to 6.24$) 0.00229 .08$ (2.57 to 32.03 ) $0.0006 \quad 2.93$ (1.70 to 5.07) $0.0001 \quad 3.70$ (2.08 to 6.57)

1.09 (0.54 to 2.21 ) $0.7997 \quad 2.79$ (1.37 to 5.68 ) $0.0045 \quad 8.49$ (2.44 to 29.57) $0.0008 \quad 2.55$ (1.48 to 4.41) $0.0008 \quad 3.55$ (2.01 to 6.28)

1.02 (0.50 to 2.08 ) 0.96532 .80 (1.37 to 5.72 ) $0.0047 \quad 8.05$ (2.28 to 28.46 ) $0.0012 \quad 2.62$ (1.53 to 4.51 ) $0.0005 \quad 3.35$ (1.90 to 5.90)

1.07 (0.52 to 2.17 ) 0.86062 .86 (1.40 to 5.82$) 0.00398 .54$ (2.42 to 30.08 ) $0.0008 \quad 2.74$ (1.59 to 4.72 ) $0.0003 \quad 3.28$ (1.86 to 5.81)

1.13 (0.55 to 2.28) $0.7442 \quad 3.00$ (1.47 to 6.14 ) $0.0026 \quad 8.95$ (2.54 to 31.57 ) $0.0007 \quad 3.00$ (1.74 to 5.16) $0.0001 \quad 3.33$ (1.88 to 5.91)

1.18 (0.58 to 2.37 ) 0.65092 .88 (1.41 to 5.85$) 0.0035 \quad 8.50$ (2.41 to 29.98$) 0.0009 \quad 2.72$ (1.59 to 4.66 ) $0.0003 \quad 3.49$ (1.98 to 6.12)

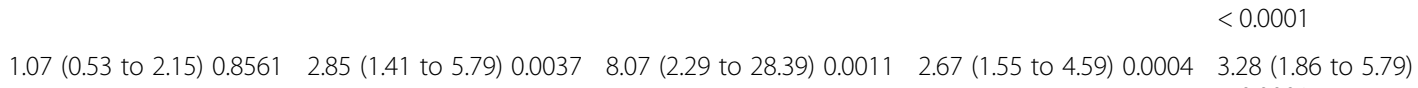

Mental quality of life (SF12)

Notes: All statistical models adjusted for age, sex, lifetime depression and country. Further adjusted models adjusted additionally for each specified confounder in turn. All analyses accounted for correlations between patients within the same health centre through inclusion in statistical models of a random effect of centre and for correlations between repeated measures within patients through inclusion of a random effect of individual $<0.0001$ $<0.0001$ $<0.0001$ $<0.0001$ $<0.0001$ $<0.0001$

3.33 (1.47 to 7.54$) 0.0040$

3.05 (1.35 to 6.85 ) 0.0071

2.85 (1.28 to 6.35$) 0.0106$

2.95 (1.31 to 6.67$) 0.0091$

3.07 (1.36 to 6.92$) 0.0068$

2.78 (1.24 to 6.24$) 0.0131$

2.97 (1.32 to 6.69$) 0.0088$

2.87 (1.29 to 6.40$) 0.0099$

3.31 (1.88 to 5.82$)$

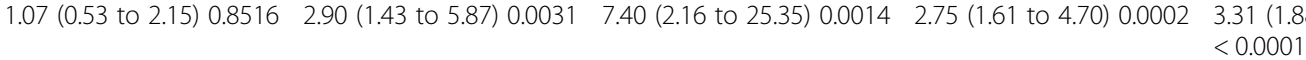

$2.62(1.18$ to 5.79$) 0.0176$

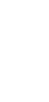


Table 4 Comparison of results from original analysis with results from sensitivity analyses to assess the possibility of bias due to missing outcome data at follow up using two different methods

\begin{tabular}{|c|c|c|c|c|c|}
\hline \multicolumn{3}{|c|}{ Onset of depression (in non-depressed people at baseline) } & \multicolumn{3}{|c|}{ Persistent depression (in depressed people at baseline) } \\
\hline Suicidal ideation & Suicide plans & Suicide attempts & Suicidal ideation & Suicide plans & Suicide attempts \\
\hline OR $(95 \% \mathrm{Cl}) p$ value & OR $(95 \%$ Cl) $p$ value & OR $(95 \% \mathrm{Cl}) p$ value & OR $(95 \% \mathrm{Cl}) p$ value & $\begin{array}{l}\text { OR }(95 \% \mathrm{Cl}) \\
p \text { value }\end{array}$ & OR $(95 \% \mathrm{Cl}) p$ value \\
\hline $\begin{array}{l}1.17(0.58 \text { to } 2.37) \\
0.6561\end{array}$ & $\begin{array}{l}3.05(1.50 \text { to } 6.24) \\
0.0022\end{array}$ & $\begin{array}{l}9.08(2.57 \text { to } 32.03) \\
0.0006\end{array}$ & $\begin{array}{l}2.93(1.70 \text { to } 5.07) \\
0.0001\end{array}$ & $\begin{array}{l}3.70(2.08 \text { to } 6.57) \\
<0.0001\end{array}$ & $\begin{array}{l}3.33(1.47 \text { to } 7.54) \\
0.0040\end{array}$ \\
\hline $\begin{array}{l}1.13(0.56 \text { to } 2.30) \\
0.7278\end{array}$ & $\begin{array}{l}2.93 \text { (1.43 to } 6.01) \\
0.0033\end{array}$ & $\begin{array}{l}8.53(2.41 \text { to } 30.15) \\
0.0009\end{array}$ & $\begin{array}{l}2.95(1.70 \text { to } 5.11) \\
0.0001\end{array}$ & $\begin{array}{l}3.60(2.02 \text { to } 6.41) \\
<0.0001\end{array}$ & $\begin{array}{l}3.15(1.38 \text { to } 7.16) \\
0.0063\end{array}$ \\
\hline $\begin{array}{l}1.10(0.61 \text { to } 1.99) \\
0.7533\end{array}$ & $\begin{array}{l}2.69(1.40 \text { to } 5.16) \\
0.0029\end{array}$ & $\begin{array}{l}7.50 \text { (1.90 to } 29.65) \\
0.0041\end{array}$ & $\begin{array}{l}3.44(1.74 \text { to } 6.79) \\
0.0004\end{array}$ & $\begin{array}{l}3.87(2.34 \text { to } 6.39) \\
<0.0001\end{array}$ & $\begin{array}{l}3.39 \text { (1.29 to } 8.94) \\
0.0134\end{array}$ \\
\hline
\end{tabular}

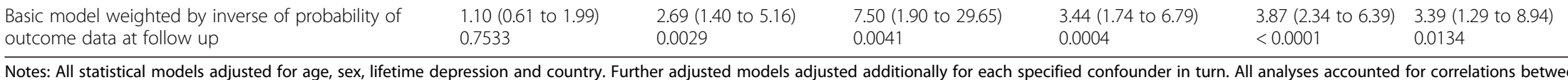
Notes: All statistical models adjusted for age, sex, lifetime depression and country. Further adjusted models adjusted additionally for each specified confounder in turn. All analyses accounted for correlations be
patients within the same health centre through inclusion in statistical models of a random effect of centre and for correlations between repeated measures within patients through inclusion of a random effect of individual 
depression in people presenting with sadness and/or anhedonia over 6 and 12 months of follow up, while ideation was a significant predictor only of persistence of depression. Although these results were attenuated after adjustment for a further set of potential confounders, the findings remained essentially the same and accord with those of Oquendo et al. [36], who conclude that suicidal behaviour is an important risk factor for major depression.

\section{Characteristics of suicidality}

While suicidal ideation were not associated with the onset of major depression in this vulnerable group of people experiencing sadness and anhedonia, suicide plans and attempts increased the odds of onset of depression three- and nine-fold respectively. In those who were already depressed at recruitment, both suicidal ideation and attempts were associated with persistent depression, but the strongest risk factor was suicide plans.

This range of self-harming behaviours [37], starting with suicidal ideas, followed by making a plan, and finally attempting suicide [38], appears to function as a continuum of severity in relation to the onset of depression in people already predisposed by the experiences of sadness and anhedonia. However, in those attenders in whom sadness and anhedonia were part of a full syndrome of major depression, suicide plans appeared to have the strongest association with lack of recovery. Despite these differences, suicidality in its various forms is an essential part of the picture and suggests that primary care physicians should pay attention to it not only in their depressed patients but also in patients who seem to have a prodromal form of the disorder. Some years ago, Arroll et al. [39] suggested that two questions on feeling down or sad, and loss of interest in things were useful screening questions to use in general practice to identify attenders with possible depression. Our results indicate that for patients who answer affirmatively, one or two further questions on suicidality may well be useful in both identifying who is about to become depressed and who is likely to recover in those already depressed.

\section{Limitations of the study}

One limitation in this study is the varying response to recruitment in each country, although the overall response was acceptable [9-11]. Furthermore, although personality disorders [40] are implicated in the onset of depression they were not included as potential risks in the development of the predict algorithm. This was because they are too complex to measure accurately in a brief prediction algorithm that was developed for use in family practice. We did not employ a specific instrument to measure suicidality but instead used questions which are part of the Depression Section of CIDI. A final limitation was the proportion of missing outcomes which might have biased our results; however, our sensitivity analysis showed that this was unlikely.

\section{Clinical implications and assessment of suicidality}

People in countries where primary medical care is free at the point of access have ready access to general practitioners and develop long-term relationships with them [41]. Thus, primary care is an ideal setting in which to collect information for use in prevention. Once physicians establish that a patient has persistent sadness and/ or anhedonia using two screening questions [39], three further questions on suicidal ideation, plans and attempts would help them to assess whether a patient 1) might be at risk of the onset of major depression or 2) if depressed, how likely they are to recover in the near future. Our data suggest that querying individuals on suicidal ideation would be clinically useful not only for persistent depression but also for the onset of depression. Family physicians do not always ask about suicide [42], despite recommendations that they should, especially in those with signs of depression [43, 44]. So this approach might provide a useful framework in which to do so.

\section{Conclusions}

As our study demonstrates, patients may have suicidal inclinations even when they do not meet the full criteria for major depression. Three questions on suicidality could help primary care professionals assess patients who have persistent sadness and/or anhedonia more closely, without necessarily establishing whether they meet criteria for major depression. The need for these additional questions is supported by findings that only a minority of primary attendees tell their physicians about their thoughts and plans regarding suicide [45, 46]. Given that screening all patients in primary care practices for suicidal behaviour is neither practicable nor useful [47], the results of our study suggest that early detection of suicidal ideation, plans and attempts in persons with the key symptoms of sadness or anhedonia may enable the general practitioner to initiate timely interventions to prevent or ameliorate major depression.

\section{Consent}

All patients gave fully informed consent for their data to be analysed and the results published.

\section{Availability of data and materials}

Inquiries regarding the data should be addressed to the corresponding author.

Competing interests

The authors declare that they have no competing interests. 


\section{Authors' contributions}

Conceived and designed the experiments: MK IN FT HM IS MX. Performed the experiments: MK IN IS HM MG MX BMK EMM CMF MJG MSC MADB CVC. Analyzed the data: RJ MK BMK. Wrote the paper: MK BMK RJ. Read and agreed to the final draft of the manuscript: BMK MK IN IS HM MG MX FTG EMM CMF MJG MSC MADB CVC RJ.

\section{Authors' information}

Berta Moreno-Küstner, PhD, Department of Personality, Assessment and Psychological Treatment, University of Malaga (Maristan Network). Malaga, Spain; Rebeca Jones, MSc, Division of Psychiatry, University College London, UK; Igor Švab, MD PhD, Department of Family Medicine, University of Ljubljana, Slovenia; Heidi Maaroos, MD PhD, Faculty of Medicine, University of Tartu, Estonia; Miguel Xavier, MD, PhD, NOVA Medical School - UNL- (Maristan Network). Lisbon, Portugal; Mirjam I. Geerlings, PhD, University Medical Center Utrecht, Utrecht, The Netherlands; Francisco Torres-González, MD PhD, CIBERSAM, University of Granada (Maristan Network). Granada, Spain; Irwin Nazareth, MBBS PhD, Department of Primary Care and Population Health, University College London Medical School (Maristan Network). London, UK. Research Council General Practice Research Framework (Maristan Network). London, UK; Emma Motrico-Martínez, PhD, International University Loyola Andalucía, Spain; Carmen Montón-Franco, MD PhD, Casablanca Health Centre (redIAPP, Aragon group). Department of Medicine and Psychiatry. University of Zaragoza. Spain; María José Gil-de-Gómez, MD, Research Unit of Primary Care of La Rioja. Spain; Marta Sánchez-Celaya, MD, Research Unit of Primary Care of Madrid. Spain; Miguel Ángel Díaz-Barreiros, MD, Vecindario Health Centre, Las Palmas. Spain; Catalina Vicens-Caldentey, MD, Son Serra Health Centre, Unit of Research in Primary Care of Balears (redIAPP, Balears group), Mallorca. Spain; Michael King, MD PhD, Division of Psychiatry, University College London (Maristan Network), London, UK.

\section{Acknowledgements}

We acknowledge the work and support of members of the Maristán network in making these collaborations possible http://redmaristan.org/.

\section{Funding}

This research was funded by a grant from The European Commission, referencePREDICT-QL4-CT2002-00683. We are also grateful for part support in Europe from: the Estonian Scientific Foundation (grant number 5696); the Slovenian Ministry for Research (grant No.4369-1027); the Spanish Ministry of Health (grant FIS references: PI041980, PI041771, PI042450) and the Spanish Network of Primary Care Research, redIAPP (ISCIII-RETICS RD06/0018) and SAMSERAP group; and the UK NHS Research and Development office for providing service support costs in the UK. We are also grateful for the support from the University of Malaga (Spain) and to Carlos García from Loyola Andalucía University (Spain)

\section{Author details}

${ }^{1}$ Department of Personality, Assessment and Psychological Treatment, University of Malaga (Maristan Network), Malaga, Spain. ${ }^{2}$ Division of Psychiatry, UCL, London, UK. ${ }^{3}$ Department of Family Medicine, University of Ljubljana, Ljubljana, Slovenia. ${ }^{4}$ Faculty of Medicine, University of Tartu, Tartu, Estonia. ${ }^{5}$ NOVA Medical School - UNLLisbon, Lisbon, Portugal. ${ }^{6}$ University Medical Center Utrecht, Utrecht, The Netherlands. ${ }^{7}$ CIBERSAM, University of Granada, Granada, Spain. ${ }^{8}$ Department of Primary Care and Population Health, University College London Medical School and Medical, Research Council General Practice Research Framework, London, UK. ${ }^{9}$ International University Loyola Andalucía, Seville, Spain. ${ }^{10}$ Centro de Salud Casablanca. (redIAPP, grupo Aragón) Departamento de Medicina y Psiquiatría, Universidad de Zaragoza, Zaragoza, Spain. ${ }^{11}$ Unidad Docente de Medicina Familiar y Comunitaria de La Rioja, La Rioja, Spain. ${ }^{12}$ Unidad Docente de Medicina Familiar y Comunitaria de Madrid, Coordinadora de Coordinadora de Direcciones de Continuidad Asistencial, Servicio Madrileño de Salud, Madrid, Spain. ${ }^{13}$ Centro de Salud de Vecindario, Gerencia de Atención Primaria de Gran Canaria, Las Palmas, Spain. ${ }^{14}$ Centro de Salud Son Serra, Unidad de Investigación de Atención Primaria de Baleares (redIAPP, grupo Baleares), Mallorca, Spain.

Received: 3 August 2015 Accepted: 9 March 2016 Published online: 06 April 2016

\section{References}

1. Bottomley C, Nazareth I, Torres-González F, Svab I, Maaroos HI, Geerlings MI, et al. Comparison of risk factors for the onset and maintenance of depression. Br J Psychiatry. 2010;196:13-7.

2. Wittchen HU, Jacobi F, Rehm J, Gustavsso A, Svensson M, Jonsson B, et al. The size and burden of mental disorders and other disorders of the brain. Euro Neuropsychopharmacol. 2011;21:655-79.

3. Andlin-Sobocki P, Jönsson B, Wittchen HU, Olesen J. Costs of Disorders of the Brain in Europe. Europ J Neurology. 2005;12:1-27.

4. Harris EC, Barraclough B. Excess mortality of mental disorder. Br J Psychiatry. 1998;173:11-53.

5. Rudd MD, Dahm PF, Rajab MH. Diagnostic comorbidity in persons with suicidal ideation and behavior. Am J Psychiatry. 1993;150:928-34.

6. Lesage AD, Boyer R, Grunber F, et al. Suicide and mental disorders: a case control study of young men. Am J Psychiatry. 1994;151:1063-8.

7. Druss B, Pincus H. Suicidal ideation and suicide attempts in general medical illness. Arch Internal Med. 2000;160:1522-6.

8. American Psychiatric Association. Diagnostic and Statistical Manual of Mental Disorders (4 ${ }^{\text {th }}$ ed) (DSM.IV). APA,1994

9. King M, Weich S, Torres-González F, Svab I, Maaroos H, Neeleman J, et al. Prediction of depression in European general practice attendees: the PREDICT study. BMC Public Health. 2006;6:6.

10. King M, Nazareth I, Levy G, Walker C, Morris R, Weich S, et al. Prevalence of common mental disorders in general practice attendees across Europe: the PREDICT study. Br J Psych. 2008;192:362-7.

11. Bellón JA, Moreno-Küstner B, Torres-González F, Montón-Franco C, GildeGómez-Barragán MJ, et al. Predicting the onset and persistence of episodes of depression in primary health care. The predictD-Spain study: methodology. BMC Public Health. 2008:8:256.

12. Bellón JA, Moreno-Küstner B, Montón Franco C, Gil Gómez MJ, Sanchez Celaya M, Díaz Barreiros MA, et al. Psychosocial and sociodemographic predictors of attrition ina longitudinal study to predict onset of episodes of major depression in primary care: The PredictD-Spain study. J Epidem and Comm Health. 2010;64:874-84.

13. Bellón JA, Luna JD, King M, Moreno-Küstner B, Nazareth I, Monton C, et al. Predicting the onset of major depression in primary care: international validation of a risk prediction algorithm from Spain. Psychol Med. 2011;41:2075-88.

14. Robins LN, Wing J, Wittchen HU, Helzer JE, Babor TF, Burke J, et al. The Composite International Diagnostic Interview. An epidemiologic Instrument suitable for use in conjunction with different diagnostic systems and in different cultures. Arch Gen Psychiatry. 1988;45:1069-77.

15. World Health Organisation. Composite International Diagnostic Interview (CIDI). Geneva: Version 2.1. WHO, 1997.

16. Rubio-Stipec M, Bravo M. La Entrevista Diagnóstica Internacional Compuesta (CIDI): Un instrumento epidemiológico adecuado para ser administrado conjuntamente con otros sistemas diagnósticos en diferentes culturas. Acta Psiquiat Psicol AmérLat. 1991;37:191-204.

17. Weich S, Lewis G. Poverty, unemployment, and common mental disorders: population based cohort study. Br Med J. 1998;317:115-9.

18. Jenkinson C, Layte $R$, Jenkinson D, Lawrence $K$, Petersen S, Paice C, et al. A shorter form health survey: can the SF-12 replicate results from the SF-36 in longitudinal studies? J Public Health Med. 1997;19:179-86.

19. Gandek B, Ware JE, Aaronson NK, Apolone G, Bjorner JB, Brazier JE, et al. Cross-validation of item selectionand scoring for the SF-12 Health Survey in nine countries:results from the IQOLA Project. International Qualityof Life Assessment. J Clin Epidemiol. 1998:51:1171-8.

20. Barbor TF, Higgins-Biddle JC, Saunders JB, Monteiro MG. The alcohol use disorders identification test: Guidelines for the use in primary health care. Second Edition, WHO: Geneva. 2001. pp40.

21. Rubio Valladolid G, Bermejo Vicedo J, Caballero Sánchez-Serrano MC, Santo-Domingo CJ. Validation of the alcohol use disorders identification test (AUDIT) in primary care. Rev Clin Esp. 1998;198:11-4.

22. Pérula de Torres LA, Fernández-García JA, Arias-Vega R, Muriel-Palomino M, Marquez-Rebollo E, Ruiz-Moral R. Validity of AUDIT test for detection of disorders related with alcohol consumption in women. Med Clin. 2005; 125:727-30.

23. Spitzer RL, Kroenke K, Williams JB. Validation and utility of a self-report version of PRIME-MD: the PHQ primary care study. Primary Care Evaluation of Mental Disorders. Patient Health Questionnaire. JAMA. 1999;282:1737-44.

24. Baca E, Saiz J, Agüera L, Caballero L, Fernández-Liria A, Ramos J, et al. Validación de la versión española del PRIME-MD: un procedimiento para el 
diagnóstico de trastornos mentales en atención primaria. Actas Españolas de Psiquiatría. 1999;27:375-83.

25. Reynolds CF, Frank E, Thase ME, Houck PR, Jennings JR, Howell JR. Assessment of sexual function in depressed, impotent, and healthy men: factor analysis of a Brief Sexual Function Questionnaire for men. Psychiatr Res. 1988;24:231-50.

26. Fink LA, Bernstein D, Handelsman L, Foote J, Lovejoy M. Initial reliability and validity of the childhood trauma interview: a new multidimensional measure of childhood interpersonal trauma. Am J Psychiatry. 1995;152: 1329-35.

27. Tyrer P. Personality disorder and social functioning. In: Measuring Human Problems: a Practical Guide (eds. Peck DF\& Shapiro CM):119-42. Chichester: Wiley \& Sons, 1990.

28. Qureshi N, Bethea J, Modell B, Brennan P, Papageorgiou A, Raeburn S, et al. Collecting genetic information in primary care: evaluating a new family history tool. Fam Pract. 2005;22:663-9.

29. Brugha T, Bebbington P, Tennant C, Hurry J. The List of Threatening Experiences: a subset of 12 life event categories with considerable longterm contextual threat. Psychol Med. 1985;15:189-1.

30. Janssen I, Hanssen M, Bak M, Bijl RV, de Graaf R, Vollebergh W, et al. Discrimination and delusional ideation. Br J Psychiatry. 2003;182:71-6.

31. Blaxter M. Health and Lifestyles. London: Routledge, 1990

32. Sokero TP, Melartin TK, Rytsälä HJ, Leskelä US, Lestelä-Mielonen PS, Isometsä ET. Suicidal ideation and attempts among psychiatric patients with major depressive disorder. J Clin Psychiatry. 2003;64:1094-100.

33. Miret M, Ayuso-Mateos JL, Sancez-Moreno J, Vieta E. Depressive disorders and suicide: Epidemiology, risk factors, and burden. Neuroscience and Biobehavioral Reviews. 2013;37:2372-4.

34. Hawton K, Casañas I, Comabella C, Haw C, Saunders K. Risk factors for suicide in individuals with depression. A systematic review. J Affect Disord. 2013;147:17-28

35. Gensichen J, Teising A, König J, Gerlach FM, Petersen JJ. Predictors of suicidal ideation in depressive primary care patients. J Affect Disord. 2010; 125:124-7.

36. Oquendo MA, Currier D, Mann JJ. Prospective studies of suicidal behavior in major depressive and bipolar disorders: what is the evidence for predictive risk factors? Acta Psychiatr Scand. 2006;114:151-8.

37. Beautrais AL. Risk factors for suicide and attempted suicide among young people. Aust N Z J Psychiatry. 2000;34:420-36.

38. LeMaster PL, Beals J, Novins DK, Manson SM. The prevalence of suicidal behaviors among Northern Plains American Indians. Suicide Life Threat Behav. 2004;34:242-54

39. Arroll B, Khin N, Kerse N. Screening for depression in primary care with two verbally asked questions: cross sectional study. Br Med J. 2003;327:1144-6.

40. Kendler KS, Kuhn J, Prescott CA. The interrelationship of neuroticism, sex, and stressful life events in the prediction of episodes of major depression. Am J Psychiatry. 2004;161:631-6.

41. Thielke S, Vannoy S, Unützer J. Integrating mental health and primary care. Prim Care. 2007;34:571-92.

42. Nutting PA, Dickinson LM, Rubenstein LV, Keeley RD, Smith JL, Elliott CE. Improving detection of suicidal ideation among depressed patients in primary care. Ann Fam Med. 2013;2:529-36.

43. Bajaj P, Borreani E, Ghosh P, Methuen C, Patel M, Crawford MJ. Screening for suicidal thoughts in primary care: the views of patients and general practitioners. Mental Health in Family Medicine. 2008;5:229-35.

44. Goodwin RD, Kroenke K, Hoven CW, Spitzer RL. Major depression, physical illness, and suicidal ideation in primary care. Psychosom Med. 2003;65:501-5.

45. Schulberg HC, Lee PW, Bruce ML, Raue PJ, Lefever J, et al. Suicidal Ideation and Risk Levels Among Primary Care Patients With Uncomplicated depression. Ann Fam Med. 2005;3:523-8.

46. Saini P, Chantler K, Kapur N. General practitioners' perspectives on primary care consultations for suicidal patients. Health Soc Care Community. 2015. doi:10.1111/hsc.12198.

47. Gaynes BN, West SL, Ford CA, Frame P, Klein J, Lohr KN. Screening for adults: a summary of the evidence for the U.S. Preventive Services Task Force. Ann Intern Med. 2004;140:822-35.

\section{Submit your next manuscript to BioMed Central and we will help you at every step:}

- We accept pre-submission inquiries

- Our selector tool helps you to find the most relevant journal

- We provide round the clock customer support

- Convenient online submission

- Thorough peer review

- Inclusion in PubMed and all major indexing services

- Maximum visibility for your research

Submit your manuscript at www.biomedcentral.com/submit
Biomed Central 